\title{
The environmental impact of workplace lighting choices in rural Oklahoma
}

\author{
P. Hebert, G. Peek, M. Kang \& R. S. Frazier \\ Oklahoma State University, USA
}

\begin{abstract}
University faculty researchers and Extension Service county educators conducted a two-part workplace lighting field study. The purpose of the field study was to explore the environmental impact of workplace lighting choices in rural Oklahoma, a state located in the south central United States of America. We care about the Environmental impact of workplace lighting choices in rural Oklahoma because in the United States, electric lighting accounts for $21 \%$ of commercial (workplace) energy use, on average (US Energy Information Administration). This makes commercial lighting a large energy user and therefore a prime system to investigate for sustainability studies.

In Part 1, the researchers visited three rural sites: (A) farm, (B) arena, and (C) repair shop. Here, researchers photo-documented the lighting, buildings, and grounds. The researchers also took empirical measurements. The researchers identified lamp types and the light reflectance values of interior and exterior building surfaces. The in situ lux measurements were compared to industry recommendations to determine need and/or waste. Sky quality meter readings were taken to determine light pollution levels. Efficacies and surface reflectance values were anticipated to influence relative energy consumption.

In Part 2, the researchers queried rural workplace stakeholders regarding their environmental stewardship related to lighting. Participants expressed their opinions during a two-hour focus group session.

The results of this study revealed that some areas were illuminated higher than recommended and utilized darker than optimum reflectances, indicating wasted light. The latest technologies were not used and therefore consumed more lumens per watt than recommended, with higher than necessary energy costs. Light pollution was found at two sites. The focus group participants revealed that lamps from their workplaces are not recycled. Rather, lamps were disposed of as
\end{abstract}


solid waste. It is critical to note that rural counties may have less access to resources. Workplace lighting efficacies, potential environmental impacts from light overages, and light pollution, as well as the potential health risks associated with mercury are causes for concern in this rural community.

Keywords: environmental impact, lighting, sustainability, rural, field study, case study, focus group.

\section{Introduction}

Researchers, innovators, activists, and policy makers worldwide provide responses to environmental issues associated with human development. The term sustainability has been used to link economic development with ecological health (New Jersey Future [2]). A common definition of sustainable development is from the World Commission on Environment and Development, which defines sustainable development as one that "meets the needs of the present without compromising the ability of future generations to meet their own needs" (World Commission on Environment and Development [3, p. 42]). The study also provides definitions for key terms, including efficacy, lamp, light reflectance value, light pollution, and county.

Many researchers and theorists support three dimensions of sustainability (Aplet et al. [4], British Columbia Round Table on the Environmental and the Economy [5], Goodland and Daly [6], Munasinghe and McNeely [7], Munro [8], Sheng [9], Viederman [10]) and suggest that the conceptual interaction and integration of environmental, economic, and social dimensions are important to sustainable development. Different interpretations of sustainability generally include the environmental, economic, and social aspects, but emphasize them to varying extents (Toman [11]). For the environmental component of sustainability, typically energy, water, land and air effects are studied (Brown et al. [12]).

Environmental issues are especially important in design development for lighting systems. Efficient light sources and appropriate light levels can contribute to the reduction of energy consumption and enhance safety and security of stakeholders (Hebert [13]). Again, it is critical to note that rural counties may have less access to resources.

As is widely known, energy production and consumption yields environmental externalities, including light pollution and increased emission of greenhouse gases (International Dark-Sky Association [14], US Environmental Protection Agency [15]). It is also important to consider lighting as it may potentially mitigate risks to health, welfare, and safety in work environments. Despite industry recommendations for electric lighting as determined by visual tasks in workplaces, lighting may be a secondary consideration in rural areas (Ludington et al. [16]). Proper workplace lighting may help minimize negative environmental impacts. 


\section{Purpose}

The purpose of this study was to explore the environmental impact of workplace lighting choices in rural locations in Oklahoma. The researchers used a 2-part field study: (1) empirical measurement at three sites (A, B, and C) and (2) focus group discussion. The intent was to gain knowledge that can impact rural workplaces and environmental outcomes. The information focuses on key areas: (1) lighting waste (using higher lux levels than recommended and/or creating light pollution) and (2) lamp disposal and lighting system sustainability issues. Researchers also explored behaviours regarding lighting and environmental sustainability in rural workplaces.

\section{Literature review}

\subsection{Key definitions}

The interdisciplinary discipline of lighting system design utilizes unique terminology. Terms applicable to the study are defined below:

- Efficacy: "Is a ratio of lumens per watt. The choice of lumens for the numerator and watts for the denominator yields several versions of efficacy" (DiLaura et al. [17, p. 13.2]).

- Lamp: "Luminaires are designed and manufactured for all common types of electric lamps. Luminaries are commonly available for these lamps: Incandescent filament including tungsten halogen and infrared lamps, Fluorescent, Compact Fluorescent, High intensity discharge including metal halide and high-pressure sodium, Light Emitting Diode (LED), Organic light emitting diodes (OLED), and Induction or electrodeless including fluorescent and metal halide lamps" (DiLaura et al. [17, p. 8.1].

- Mercury fluorescent lamp component "The fluorescent lamp is a lowpressure gas discharge source, in which light is produced predominantly by fluorescent powders, also known as phosphor, that are activated by UV energy generated by mercury arc" (DiLaura et al. [17, p. 7.26]).

- Cutoff angle of a luminaire: "The angle, measure up from nadir, between the vertical axis and the first line of sight at which the bare source is not visible" (Rea [18, pp. G-9]).

- $\quad$ Light reflectance value (LRV): "Is the ratio of exitant to incident luminous flux. It may or not be specified with regard to the incident or exitant directions... Reflectance is affected by the geometry, wavelength and polarization of the incident flux" (DiLaura et al. [17, p 5.15]). It refers to visible light reflected from surface by light source.

- Light pollution: "Light that is directed skyward, hindering or eliminating the view of the starlit sky on clear nights" (DiLaura et al. [17, p 19.7]).

- Light trespass: “...light that leaves a site and strikes a neighboring property, which may be considered a nuisance." (DiLaura et al. [17, pp. 19.7-19.8]).

- Workplace: the office, factory, etc. where people work (Merriam-Webster 19]). 
- County: "The largest territorial division for local government within a state of the United States" (Merriam-Webster [20]).

\subsection{Why do we care?}

In the United States, electric lighting accounts for, on average, $21 \%$ of commercial (workplace) energy use (US Energy Information Administration [1]). This makes commercial lighting a large energy user and therefore a prime system to investigate for sustainability studies. There are environmental, economic, and social impacts associated with any product creation and use. This is the traditional basis of determining the sustainability of appliances such as lighting (World Commission on Environment and Development [3]).

The study is important for four main reasons. First, there are relatively few rural lighting studies in literature. Second, rural commercial lighting end users have somewhat different needs relative to urban users (DiLaura et al. [17]). Third, rural action in one U.S. state may potentially impact areas in other parts of the world. For example, lighting choices made by workplace stakeholders in Oklahoma may necessitate rare earth metal mining in African countries for the specified lighting components. The nature of modern product manufacturing is such that materials and associated processes are globally derived. Fourth, current workplace lighting choices may affect the three dimensions of sustainability social, financial, and environmental. Relatively inefficient lighting consumes more energy and consequently more fossil fuels. The implications for greenhouse gas, climate change, and local air pollution are straightforward.

Of additional concern is the "end of life" or disposal phase for lighting systems, which may also have consequences for the future users. Additionally, remediation costs could be a troublesome burden on future generations. During the 1980s and 1990s, many rural landfills closed due to the inability to meet Resource Conservation and Recovery Act (RCRA) Subtitle D requirements for household and small quantity generator wastes (Eilrich et al. [21]). This limiting of rural landfill facilities may lead to improper disposal of wastes.

Today's lighting choices will have direct influence on lighting system costs (energy, replacement bulbs, etc.) in the present and future. There are often tradeoffs associated with energy use and lamp costs. The first costs of more modern lamps can be many times the cost of the old technology. Disposal costs for the modern lamps may also be higher due to certain hazardous metals and plastics not found in the older lamps (US Environmental Protection Agency [22]). It is reasoned that the lower energy use over the lamp life produces more environmental and economic benefit than the aforementioned burdens.

\section{Methods}

In Spring 2012, the interdisciplinary team conducted a 2-part field study to explore the environmental impact of workplace lighting choices in a rural county in Oklahoma. Oklahoma is a state located in the south central part of the United States of America. The researchers represented the fields of Family and 
Consumer Sciences Extension, Agriculture Extension (Biosystems Engineering), and Human Sciences (Interior Design-Facility Management). The rural sites were chosen via convenience sampling. In this study, five main research questions regarding environmental impacts were considered:

1. Will artificial ambient light levels at rural workplace site differ from industry recommendations?

2. Will sustainable lighting systems be utilized in rural workplace?

3. Will rural workplaces create light pollution?

4. Will rural workplaces utilize good environmental practices regarding lamp disposal?

5. Are rural workplace stakeholders concerned about sustainability regarding (a) people, (b) prosperity, and (c) the planet?

\subsection{Part 1 (empirical measurement)}

Both interior and exterior lighting were examined at each site (A, B, and C).

- $\quad$ Site A: Farm

- Site B: Arena

- $\quad$ Site C: Repair shop

The researchers visited sites during daytime and evening hours. The existing ambient illumination supported a variety of visual tasks, including vehicle service and repair; and the exhibition, general farm work, and care and housing of livestock. The workplaces accommodated potentially dangerous interior tasks. Exterior task lighting was considered to potentially aid safety (providing workplaces free from harm and the "identification of any hazards or obstructions" (Rea [18, pp. 29-16]), and security (creating a perception of security and protecting people and property from criminal activities) (Rea [18, pp. 29-17]).

\subsubsection{Photo documentation, light level measurements and sky quality}

Each site was visited twice on one spring day, during daytime and evening hours. Researchers photo-documented the interior and exterior lighting, buildings, and grounds. It was important to document the lighting in context to show the lights' relationship with the workplace

The researchers took nighttime empirical light level measurements in the exterior and interior of the workplaces utilizing an Extech Model 401025 digital lux meter. Light levels produced by electric lighting on horizontal and vertical task surfaces were recorded. The researchers also used a digital sky quality meter (Unihedron SQM) to measure sky quality at night. The higher the sky quality value, the lower the level of light pollution. For example, a high value indicates a dark sky. A lower value indicates a more light polluted sky (Walker et al. [23]).

The researchers identified lamp types via visual inspection of installed light sources and examinations of replacement stock found in maintenance rooms. Light reflectance values (LRV) of exterior and interior building surfaces were estimated by the researchers. Surface finishes were compared to the LRV values on a Sherwin-Williams paint chip chart. The researchers then compared the in 
situ lux measurements to industry lighting recommendations to determine compliance, "need" or "waste".

\subsection{Part 2 (focus group discussion)}

In Part 2, the researchers queried participants regarding their environmental stewardship related to lighting. Study aims and procedures were explained. Subjects signed a consent form acknowledging agreement to participate, awareness of their rights as participants, and indicating permissions for recording and use of their data. No inducements were given. The session lasted two hours.

\section{Findings}

\subsection{Part 1 (empirical measurement of exterior and interior)}

None of the sites experienced precipitation the night of the field study and a new moon with $10 \%$ face contributed negligibly to light meter readings. A total of 114 light level (footcandles, lux) readings were gathered at equidistant points, following industry methods. As shown in Tables 1 and 2, artificial illumination was measured in both the exterior and the interior of buildings at all three sites and additional relevant factors were observed and recorded. Empirical measurements were compared to industry standards.

As noted in Table 1, at Site A (small farm), the general exterior surroundings were found to be dark. The LRV (22) of the exterior surfaces were categorized as dark by the researchers. For the exterior of the farm building, both safety and security were considered. Regarding safety, measured in the horizontal plane on grade, the IES (DiLaura et al. [17]) recommendation was $0.5 \mathrm{fc}(5.4 \mathrm{~lx})$. While the maximum field-measured data points $(0.6 \mathrm{fc}(6.5 \mathrm{~lx}))$ exceeded the standard by $20 \%$, indicating waste. The minimum level $(0.2 \mathrm{fc}(2.2 \mathrm{~lx}))$ and the mean level $(0.4 \mathrm{fc}(4.3 \mathrm{~lx}))$ were below the standard by $60 \%$ and $20 \%$ respectively, indicating need.

Regarding security, measured in the vertical plane, IES recommends a range of 0.5-2.0 fc (5.0 to $20.0 \mathrm{~lx})$. The maximum (4.3 fc (46.31 lx)) exceeded the IES recommended standard by $115 \%$, indicating waste. The mean $(1.0 \mathrm{fc}(10.8 \mathrm{~lx}))$ complied with the standard. The minimum measurement $(0.2 \mathrm{fc}(2.2 \mathrm{~lx}))$ fell $60 \%$ below the standard, indicating need.

The LRV of the farm building interior surfaces were in the mid-range (54) for the ceiling and relatively low (22) for the walls and floor. The main visual task performed on the interior of the farm building was tending to the livestock being housed within, mostly horses. The horizontal light level recommended for this visual task was $7.0 \mathrm{fc}(7.5 \mathrm{~lx})$. The maximum $(0.5 \mathrm{fc}(5.4 \mathrm{~lx}))$, mean $(0.4 \mathrm{fc}(4.3 \mathrm{~lx}))$, and minimum (0.3 fc (3.2 lx)) field-measured levels fell 29\%, $43 \%$ and $57 \%$ below the recommendation, indicating need.

At Site B (arena), the general exterior surroundings were found to be dark. The LRV (85) of all of the building exterior surfaces of the arena were categorized as light. Regarding exterior safety, measured in the horizontal plane 


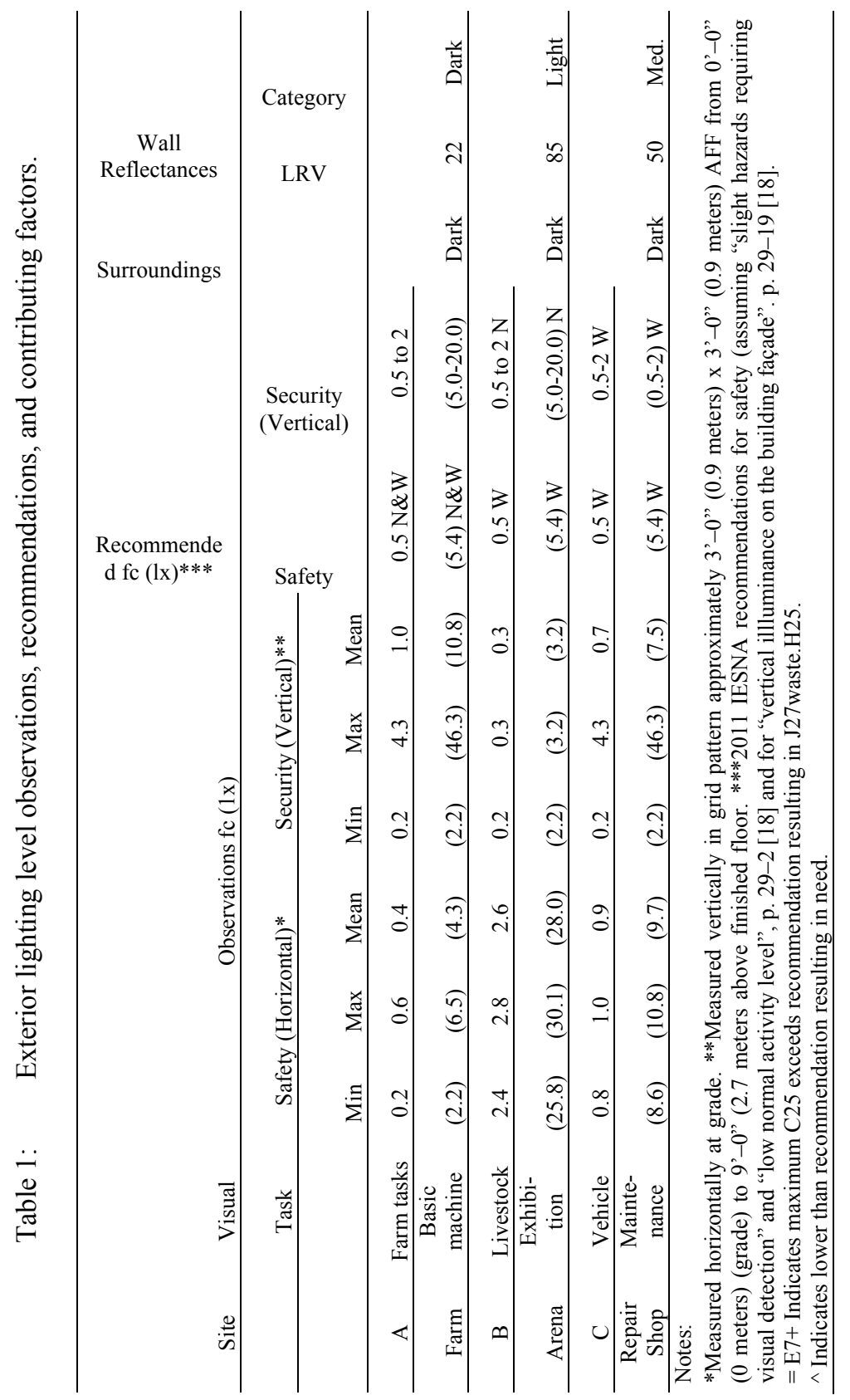


Table 2: Interior lighting observations*, recommendations and contributing factors.

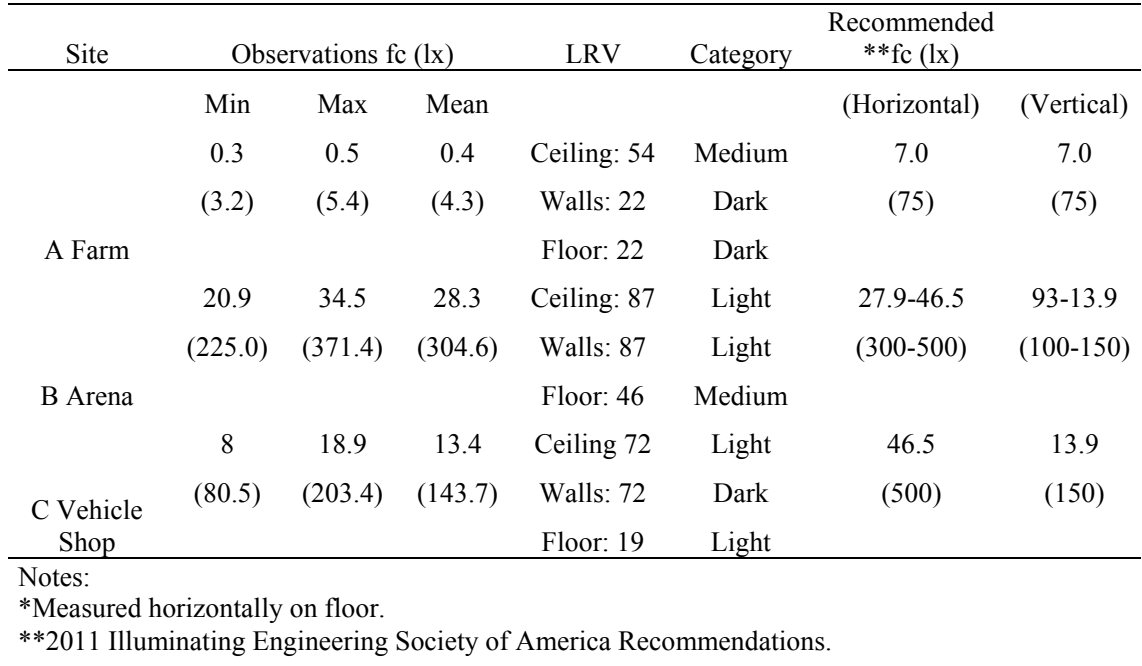

on grade, the IES recommendation was $0.5 \mathrm{fc}(5.4 \mathrm{~lx})$. The maximum $(2.8 \mathrm{fc}$ $(30.1 \mathrm{~lx}))$, mean $(2.6 \mathrm{fc}(28.0 \mathrm{~lx}))$ and minimum $(2.4 \mathrm{fc}(25.8 \mathrm{~lx}))$ field-measured levels are $460 \%, 420 \%$, and $380 \%$ above the recommended standard. Regarding exterior security, measured in the vertical plane, the IES recommended a range of $0.5-2.0 \mathrm{fc}(5.0$ to $20.0 \mathrm{~lx})$. The field-measured maximum $(0.3 \mathrm{fc}(3.2 \mathrm{~lx}))$, mean $(0.3 \mathrm{fc}(3.2 \mathrm{~lx}))$, and minimum (0.2 fc (2.2 lx)) levels fell $40 \%, 40 \%$ and $60 \%$ below the bottom of the recommended range, indicating need.

The LRV of the arena building interior surfaces were relatively high (87) for the ceiling and walls and in the mid-range (46) for the floor. The main visual tasks on the interior of the building were to view livestock exhibitions during such events as rodeos and horse shows. The light levels recommended for this visual task were $27.9-46.5$ fc $(300-500 \mathrm{~lx})$. While the maximum (34.5 fc (371.4 lx)) and mean (28.3 fc (304.6 lx)) levels measured in the field fell within the recommended range, the minimum (20.9 fc (225.0 lx)) level was fell $25 \%$ below the bottom of the recommended level, indicating need.

At Site $\mathrm{C}$, a vehicle repair shop, the overall exterior surroundings were found to be dark and the LRV (50) of all of the building exterior surfaces were categorized as medium by the researchers. For the exterior of the building, both safety and security were considered. Regarding safety, measured in the horizontal plane, the IES recommendation was $0.5 \mathrm{fc}(5.4 \mathrm{~lx})$. The maximum $(1.0 \mathrm{fc}(10.8 \mathrm{~lx}))$, mean $(0.9 \mathrm{fc}(9.7 \mathrm{~lx}))$ and minimum $(0.8 \mathrm{fc}(8.6 \mathrm{~lx}))$ field measured levels exceeded the recommendation by $100 \%, 80 \%$, and $60 \%$, respectively, indicating waste. 
Regarding security, measured in the vertical plane, the IES recommended a range of $0.5-2.0 \mathrm{fc}(5.0$ to $20.0 \mathrm{~lx})$. The field-measured maximum (4.3 fc $(46.3 \mathrm{~lx})$ ) level exceeded the recommendation by $115 \%$, indicating waste. The mean $(0.7 \mathrm{fc}(7.5 \mathrm{~lx}))$ fell within the recommended range. The minimum $0.2 \mathrm{fc}(2.2 \mathrm{~lx}))$ fell $60 \%$ below the recommended range, indicating need. The main visual task on the interior of this building was vehicle maintenance. The IES light level recommended for this visual task was $46.5 \mathrm{fc}$ (500 lx). The LRV of the repair facility interior surfaces were relatively light (72) for the ceiling and walls and relatively low (19) for the floor. The field-measured maximum (18.9 fc $(203.4 \mathrm{~lx})$ ), mean (13.4 fc (143.7 lx)), and minimum ( $8 \mathrm{fc}(80.5 \mathrm{~lx})$ ) light levels fell $59 \%, 71 \%$, and $83 \%$ below the recommended level, respectively indicating need.

\subsection{Part 1 (empirical measurement of sky quality)}

A total of 75 sky quality readings were taken at equidistant points adjacent to buildings but not directly below light fixtures, per industry-recommended methods. Sky quality measurements across sites varied, as seen in Table 3.

Table 3: Site conditions and exterior lighting.

\begin{tabular}{|c|c|c|c|c|c|c|c|c|c|}
\hline \multirow[t]{2}{*}{ SITE } & \multicolumn{3}{|c|}{$\begin{array}{l}\text { Sky quality reading } \\
\left(\mathrm{mags} / \text { arc second }^{2}\right)\end{array}$} & \multirow[t]{2}{*}{$\begin{array}{l}\text { Cut } \\
\text { off }\end{array}$} & \multirow[t]{2}{*}{ Light sources } & \multicolumn{3}{|c|}{ Weather } & \multirow[t]{2}{*}{$\begin{array}{l}\text { Moon } \\
\text { phase }\end{array}$} \\
\hline & Min & Max & Mean & & & $\begin{array}{l}\text { Cloud } \\
\text { Cover }\end{array}$ & Precip. & Temp ${ }^{\circ} \mathrm{F}$ & \\
\hline $\begin{array}{c}\text { A } \\
\text { Farm }\end{array}$ & 16.94 & 20.55 & 19.7 & No & & & & & \\
\hline $\begin{array}{c}\text { B } \\
\text { Arena }\end{array}$ & 17.73 & 19.87 & 18.82 & No & $\begin{array}{l}\text { High Pressure } \\
\text { Sodium }\end{array}$ & & & & \\
\hline $\begin{array}{c}\text { C } \\
\text { Vehicle } \\
\text { Shop }\end{array}$ & 19.14 & 20.13 & 19.39 & No & $\begin{array}{c}\text { Incandescent } \\
\text { (Quartz } \\
\text { Halogen) }\end{array}$ & $\begin{array}{c}\text { Scattered } \\
\text { clouds }\end{array}$ & None & $\begin{array}{c}\text { Min: } 69.8 \\
\text { Max: } 89.6 \\
\text { F }\end{array}$ & $\begin{array}{c}\text { New } \\
\text { Moon } \\
10 \%\end{array}$ \\
\hline
\end{tabular}

The minimum (16.94 mags/arcsecond $\left.{ }^{2}\right)$ and the maximum (20.55 mags/arcsecond ${ }^{2}$ ) across sites were found at Site A. The mean of sky quality at Site A was $19.7 \mathrm{mags} / \mathrm{arcsecond}^{2}$, at Site B was $18.82 \mathrm{mags} / \mathrm{arcsecond}^{2}$ and at Site C was 19.39 mags/arcsecond ${ }^{2}$. The minimum reading at Site B was found to be $17.73 \mathrm{mags} / \operatorname{arcsecond}^{2}$. Although some light pollution was found at two sites, Sites A and B, sky quality means of all three sites means were categorized by the researchers as generally fair to good. Visual inspection revealed that none of the site utilized the recommended cutoff fixture distributions.

\subsection{Part 2 (focus group discussion)}

Part 2 consisted of a workplace stakeholder focus group session. Researchers obtained Institutional Review Board (IRB) approval to conduct focus group. The 
purpose of the focus group was to discuss lighting and environmental sustainability in their workplaces. Participants included rural business representatives from each of the three sites explored during Part 1. The focus group participants included: (1) petroleum landman, (2) county safety director, (3) safety coordinator, (4) farmer-rancher, and (5) county commissioner. All $(5,100 \%)$ were male. The information flow was generally from the participants to the researchers. During discussion, the researchers were also able to answer technical lighting questions as they emerged. As noted by Straka et al. [24], dual information flow is important during focus groups.

\subsection{Focus group themes}

Five main themes emerged from the focus group. First, participants agreed that lighting is important to workers. Comments included that good lighting helps reduce stress at work and can boost morale; “...being comfortable, decreased risk of injury and fatigue..." It was also agreed that lighting is important in the community. Participants stated that lighting serves to help rural workers complete work tasks during times of stress (i.e. storms). "Night operations usually occur in emergencies..."

Second, participants expressed their need for enough lighting to reduce thefts. Third, unlike many of their urban business counterparts, some participants wanted to project only a discreet nighttime presence for their rural businesses. Some wanted to minimize their workplace night-lighting footprint. This could also minimize light pollution and light trespass.

Fourth, lighting waste disposal was also an issue. Responding to questions from the researchers, participants revealed that none $(0,0 \%)$ currently recycled the used lamps from their workplaces. Rather, fluorescent lamps, containing mercury, were disposed of as solid waste. Participants were unaware of any local sustainable disposal options. Regarding hazardous waste facility use, one participant indicated, "We'd like to know the regs [sic]."

Finally, participants agreed that sustainability is important. One comment was that "Farmers and ranchers are some of the biggest environmentalists." Yet among these rural business participants, overall attitudes varied with some perceived disproportionate economic burdens associated with taking environmental actions. Some comments invoked a restrained response to environmental activity, stating that a clean environment is important, but rural economic considerations are also important.

\section{Discussion and conclusions}

The current study utilized relatively simple and repeatable methods with portable, relatively inexpensive instruments to explore existing illumination installations, perceptions, attitudes, and behaviors in rural workplaces.

This paper begins to fill a gap in the literature regarding empirical case studies of rural workplace lighting choices and associated environmental impacts. This study utilized Attardi's [25] theoretical framework, which 
explained that consumers who became aware of sustainable lighting would accept it and then prefer it.

The factors contributing to the support of workplace tasks include the visibility factors in the workplace (i.e. surface reflectances, lighting type, light level, etc.), and users' demographic factors. The IES standards utilized in the current study were selected by the researchers for the middle-range age group, the "visual age" of the majority of workers at the sites were assumed to be between 25 and 65 years of age.

Regarding the five main research questions considered in the study, the following are the researchers' evaluations:

1. Will artificial ambient light levels at rural workplace sites differ from industry recommendations? In many case, the light levels did not comply with IES recommendations.

2. Will sustainable lighting systems be utilized in rural workplace? In some cases unsustainable (low efficacy, short life-time, mercury, etc.) light sources and less than optimum surface reflectances were used.

3. Will rural workplaces create light pollution? At some sites, some evidence of light pollution was found.

4. Will rural workplaces utilize good environmental practices regarding lamp disposal? During the Focus Group sessions, participants reported they did not always utilize good environmental practices (i.e. disposal).

5. Are rural workplace stakeholders concerned about sustainability regarding people, prosperity, and the planet? Based on comments made during the Focus Group sessions, it was determined that stakeholders' concerns for people, prosperity and the planet were mixed.

Local facilitation and participation of the focus group session was critical to its success. The focus group session revealed that the rural stakeholder participants are independent thinkers and may not be as familiar with environmental regulations or have as much access to environmental services as their urban counterparts. Again, it is critical to note that rural counties may have less access to resources.

The researchers recommend that new workplaces be renovated to meet current industry lighting standards. Rural workplaces should implement environmental impact studies and utilize best practices regarding light sources, cutoff fixtures, and lamp disposal. Current users of more workplaces should be surveyed to determine lighting system recycling efforts, challenges, and future needs. A longitudinal study of several rural workplaces is recommended. Additional studies with geographical variance and a range of user group demographics (age, gender, socio-economic, education level groups) are recommended.

\section{References}

[1] US Energy Information Administration Table browser. http://www.eia. gov/oiaf/aeo/tablebrowser/ - release=AEO2014ER\&subject=0-AEO2014E $\mathrm{R} \&$ table $=5$-AEO2014ER\&region $=0-0 \&$ cases $=$ full2013d102312a,ref2014 er-d102413a (accessed January 2). 
[2] New Jersey Future Living with the future in mind: Goals and indicators for New Jersey's quality of life. http://www.njfuture.org/pdf/NJF_SSR.pdf (accessed January 2).

[3] World Commission on Environment and Development, Report of the World Commission on environment and development: Our common future. Author: Geneva, SW, 1987.

[4] Aplet, G. H.; Johnson, N.; Olson, J. T.; Sample, V. A., Defining sustainable forestry. Island Press: Covelo, CA, 1993.

[5] British Columbia Round Table on the Environmental and the Economy, Sustainability: From ideas to action. Author: Victoria, BC, 1993.

[6] Goodland, R.; Daly, H., Environmental sustainability: Universal and nonnegotiable. Ecological Applications, 6(4), pp. 1002-1017, 1996.

[7] Munasinghe, M.; McNeely, J., Key concepts and terminology of sustainable development. In Defining and measuring sustainability: The biogeophysical foundations, Munaginghe, M.; Shear, W., Eds. The World Bank: Washington, DC, 1995.

[8] Munro, D. A., Sustainability: Rhetoric or reality. In A sustainable world: Defining and measuring sustainable development, Trzyna, T. C., Ed. International Center for the Environmental Policy: Sacramento, CA, 1995; pp. 27-35.

[9] Sheng, F., National economic indicators and sustainable development. In A sustainable world: Defining and measuring sustainable development, Trzyna, T. C., Ed. International Center for the Environmental Policy: Sacramento, CA, 1995; pp. 216-229.

[10] Viederman, S., Knowledge for sustainable development: What do we need to know. In A sustainable world: Defining and measuring sustainable development, Trzyna, T. C., Ed. International Center for the Environmental Policy: Sacramento, CA, 1995; pp. 36-43.

[11] Toman, M. A., Economics and sustainability: Balancing trade-offs and imperatives. Land Economics, 70(4), pp. 399-413, 1994.

[12] Brown, B. J.; Hanson, M. E.; Liverman, D. M.; Merideth, R. W., Global sustainability: Toward definition. Environmental Management, 11(6), pp. 713-719, 1987.

[13] Hebert, P., A study of the impacts of existing artificial optical radiation at student housing sites In Sustainable development and planning $V$, Brebbia, C. A.; Beriatos, E., Eds. WIT Press: Southampton, 2011; p. 250.

[14] International Dark-Sky Association The problem with light pollution. http://www.darksky.org/assets/documents/is001.pdf (accessed January 2).

[15] US Environmental Protection Agency Climate change basics. http://www.epa.gov/climatechange/basics/ (accessed June).

[16] Ludington, D. C.; Johnson, E. L.; Kowalski, J. A.; Mage, A. L.; Peterson, R. A., Dairy farm energy management guide: California. Southern California Edison: CA, 2004.

[17] DiLaura, D. L.; Houser, K. W.; Mistrick, R. G.; Steffy, G. R., The lighting handbook. 10th ed.; Illuminating Engineering Society of North America: New York, 2011. 
[18] Rea, M., The IESNA lighting handbook. 9th ed.; Illuminating Engineering Society of North America: New York, NY, 2000.

[19] Merriam-Webster Workplace. http://www.merriam-webster.com/dictionary/workplace (accessed Jan. 2).

[20] Merriam-Webster County. http://www.merriam-webster.com/dictionary/county (accessed Jan. 2).

[21] Eilrich, F. C.; Doeksen, G. A.; Kimbell, S. L.; Lawler, M. K.; Rood, R. F., A guidebook for rural solid waste management services: MP-167. Oklahoma Cooperative Extension Service: Stillwater, OK, 2002.

[22] US Environmental Protection Agency Recycling and disposal after a CFL burns out. http://www2.epa.gov/cfl/recycling-and-disposal-after-cfl-burnsout (accessed January 2).

[23] Walker, C.; Bueter, C.; Hurst, A.; White, V.; Patten, K. GLOBE at night: Using sky quality meters to meaure sky brightness. http://www.noao.edu/outreach/press/pr08/files/GaN_SQM.pdf (accessed January 2).

[24] Straka, T. J.; Nespeca, M.; Howell, M. B.; Irwin, H. T., The Focus Group as a Demonstration Technique. Journal of Extension [On-line], 47 (6) Article 6TOT4. Available at http://www.joe.org/joe/2009december/tt4. php. 2009.

[25] Attardi, W., Educating the general public on lighting a good idea? In Illuminating Engineering Society of North America Centennial Conference, New York, NY, 2006; p. 3. 